\section{Mixed agricultural produce}

\section{J.B. Owen}

Research and Development in Agriculture. Chief editor C.T. Whittemore. Longman. 3/yr. UK£45, North America $\$ 90$.

THIS new publication fills a gap in the literature on agriculture between the established journals, which concentrate mainly on the research side, and the multitude of more ephemeral materials covering the development end of the spectrum. As far as can be assessed from the four numbers available for review, the practice lives up to the theory of the editor's objectives as expressed in the first issue.

The pattern of content developed thus far is a useful mixture of reviews with a core of papers, not commonly found in

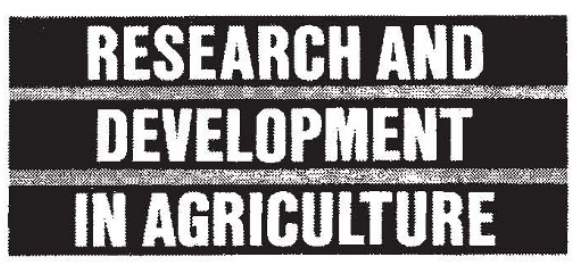

other journals, dealing with such topics as modelling and surveys. In the systems modelling field, for example, contributions vary from discussion of principles to the exposition of the features of a particular model of sheep production and its application. Some, more conventional papers describing experiments in the development arena have also appeared.

Each issue, of some $60-70$ pages, contains about eight articles and a book review section, the technical contributions ranging from longish reviews to shorter papers of five pages or less. The quality of the contents is properly enhanced by an attractive yet functional style of presentation, with adequate figures and tables.

Research and Development in Agriculture has set itself a high standard in the opening issues. It will have a secure future if it can maintain its initial momentum, appeal to a general readership and attract the busy young authors working in this thriving area. Appropriately, it has already published some overseas contributions, such as an economic analysis of research and development priorities in Mexican pig production, but one would expect to see the geographical scope expanding further from its Edinburgh base as the journal achieves wider recognition.

For the future, the editors might consider a regular "matters arising" section. Potential authors would also welcome an indication of the time between receipt and publication of manuscripts.

J.B. Owen is a Professor in the Department of Agriculture, University College of North Wales, Bangor, Gwynedd LL572DG, UK.

\section{Food for a science}

\section{Ian Morton}

Food Microbiology. Editor B.H. Kirsop. Academic. 4/yr. UK £48, North America $\$ 98$ (for 1985).

International Journal of Food Microbiology. Editor-in-chief H. Søgaard. Elsevier. $6 / y r$. Dfl.274, \$94.48.

DURING the past few years, attention in food microbiology has been directed not only to the identification and quantification of food poisoning organisms (or their toxins) but to changes in the composition of the bacterial population by external means. These two new journals reflect this broadening of the subject, and have other points in common: both were launched at the beginning of 1984 , and both have an international editorial board.

In Food Microbiology, we have in each issue an interesting and provocative editorial together with a correspondence section. The editor clearly states his intention that not only will original papers be considered by the journal, but also "state of the art" reviews will be published, along with book reviews. These aims have been met successfully in the first year. Original papers dealing with Clostridium perfringens and also Campylobacter jejuni have appeared, as has a bacteriological survey of water and ice for general uses in Thailand. It is stimulating to read reviews such as this, and to realize that food micro-

\section{Specialist sensation}

\section{A.G. Brown}

Somatosensory Research. Editor Lawrence Kruger. Guilford, 200 Park Avenue South, New York, NY 10003, USA. 4/yr. North America $\$ 75$ (institutional), \$50 (individual); elsewhere $\$ 90$ (institutional), $\$ 65$ (individual).

Somatosensory Research aims to cover "the entire range of investigations related to somatic sensation and its neural mechanisms". It has a strong North American bias: 12 of the 22 members of the editorial board and 35 of the first 41 papers are from North American laboratories (14 of the papers from people on the editorial board). The first two volumes cover a wide range of subject matter, including electron microscopic immunocytochemistry, pathway tracing, electrophysiology and psychophysics. The papers vary wildly in quality, some being poor and others sound. Personally I found about 20 per cent of the contents of some interest.

The typeface is easy to read and the journal is produced on high-quality glossy paper. Line drawings are good but some half-tone illustrations leave a lot to be ๑) 1985 Nature Publishing Group biologists are becoming aware that they must take into account a multitude of factors bearing on their science. It is good, too, to see that when strains used for biotechnological processes are described, they must be made available to colleagues.

International Journal of Food Microbiology, an official publication of the International Union of Microbiological Societies and the International Committee on Food Microbiology and Hygiene, is a more traditional research-paper journal. The standard of refereeing is clearly high and the papers deal with bacterial and mould species of considerable interest to the food scientist; for example Yersinia species are described in various pork products and a number of papers deal with different Campylobacter species. The contributions cover a wide range of food products, ranging from fish and oysters to milk and yams.

With the stress now being laid upon food safety and prevention of food poisoning, both of these journals are likely to play important albeit differing roles. Despite the cost, any laboratory or teaching establishment at the tertiary level which deals with food and nutrition can ill afford to be without them. Food and drink are essential to life, and we should hope that food microbiologists will read the papers in these two journals and will play a full role in the development of their subject. $\square$

Ian Morton is Professor in the Department of Food Science and Nutrition at King's College London $(K Q C)$, Campden Hill Road, London W8 $7 A H, U K$.

desired (that may not be the fault of the publishers, as other half-tones are excellent). Unusually, there is no indication of when a manuscript was submitted or accepted. Such information I always find interesting, but more importantly without it intending authors have no way of telling how long it might take to have a paper published.

All of the contributions appearing in the first two volumes could have found a home in one of the established journals. Indeed, whether or not one thinks there is a subdiscipline of somaesthesis is a subjective matter. There would, perhaps, have been more sense in a journal of sensory research, covering the whole range, since cross-fertilization of ideas from one modality to another is of obvious importance. But, as the vision fraternity has long been divorced from the rest of us, this idea would probably be a non-starter.

This journal, then, is in the modern fashion of specialist publications, and provides a repository for research data in a rapidly expanding area. Unfortunately, what are needed are some unifying concepts in neuroscience, not further schisms.

A.G. Brown is Professor of Veterinary Physiology at the Royal (Dick) School of Veterinary Studies, University of Edinburgh, Summerhall, Edinburgh EH9 IQH, UK. 